\title{
Social geography of Rhinoscleroma and qualitatively and quantitatively abnormal cell-mediated immunity
}

\begin{abstract}
Rhinoscleroma is a progressive chronic granulomatous disease of the upper respiratory tract that may extend to the tracheobronchial tract. It is common belief that the pathology is determined by Klebsiella Rhinoscleromatis; however, in the authors' opinion, the infection with Klebsiella Rhinoscleromatis may not represent the only etiopathogenic factor of the disease.

Rhinoscleroma is reported in many countries, but has a peculiar social and geographic distribution, in that it assumes an endemic character only in some regions of the Middle East, Eastern Europe, North and Sub-Saharan Africa, Indonesia, Central and South America. In Europe, most of the cases have been reported in Poland, Hungary and Romania. In Italy, rhinoscleroma is almost exclusively located in the southern and island regions. Rhinoscleroma is predominantly reported in rural areas, in the presence of poor socio-economic conditions, which according to many authors would be a cofactor triggering the disease.

In this article, the authors review some inconsistencies in etiology, histology and epidemiology of rhinoscleroma that support a role of intrinsic factors, possibly of genetic origin, in giving rise to the disease, and suggest possible lines of research to distinguish between extrinsic and intrinsic factors as determinants for rhinoscleroma.
\end{abstract}

Keywords: Rhinoscleroma, Klebsiella Rhinoscleromatis, Immune system, Geographical evidences.

Abbreviations: Rhinoscleroma (RS), Klebsiella Rhinoscleromatis (KR), capsular antigens (K), somatic antigens $(\mathrm{O})$ 


\section{Introduction}

Rhinoscleroma (RS) is considered a rare infection (Di Carlo et al., 2001; Fernandez-Vozmediano et al., 2004; Kim et al., 2003; Quevedo, 1949; Tan et al., 2012), that is endemic in some regions of the Middle East, Eastern Europe, North and Sub-Saharan Africa, Indonesia, Central and South America. Most of the cases described in Europe are reported in Poland, Ukraine, Hungary and Romania. In Italy, RS can be found in small outbreaks almost exclusively located in the southern and island regions. RS is found predominantly in rural areas and in the presence of poor socio-economic conditions (Efared et al., 2018). It is common belief that this condition is determined by Klebsiella Rhinoscleromatis (KR); however, the simple contagion with KR may not be sufficient to determine the disease in humans and animals. Contamination appears to be facilitated by crowding, poor hygiene and poor nutrition, but this hypothesis does not explain why the disease affects women more often than man $(\mathrm{M} / \mathrm{F}$ ratio=1:13), people in the same family and favors the second to third decade of life.

There are many immune system abnormalities found in patients affected by RS (Airas and Jalkanen, 1996; Berron et al., 1988; Griswold et al., 1983; Hardy et al., 1991; Modlin et al., 1983; Tedder et al., 1989). In peripheral blood samples it has been observed a relative reduction of the CD4+ cells, an absolute increase of the CD8+ cells with an inversion of the CD4+/CD8+ ratio, an absolute increase of the CD56+ cells and cytotoxic cells that co-express CD8+ and CD56+ antigens. In tissues, a granuloma with an anomalous architecture has been observed; approximately one third of the T lymphocyte population showed a CD8+ profile and two thirds expressed a CD4+ profile. A proven explanation for these epidemiologic, hematologic and histologic evidences has not yet been formulated; however, two hypotheses have been proposed. According to the first hypothesis, KR could induce an alteration of the immune system, thus allowing the evolution of the infection into a chronic form. The second is that the immune system, already altered by other unknown mechanisms, allows KR attacking the body (Toppozada et al., 1984). In this narrative review, the authors present 
their hypothesis to explain the etiological, epidemiological and histological anomalies and incongruences found in RS.

\section{Discussion/Observations}

\subsection{Etiology}

$\mathrm{RS}$ is a progressive chronic granulomatous disease of the upper respiratory tract that in some cases may extend to the tracheobronchial tract. The term "Rhinoscleroma" was coined in 1870 by Von Hebra; a few years later in 1882 Von Frisch identified the causative agent of this lesion as a gramnegative coccobacillus, now known as KR (Ahmed et al., 2015; Barraud, 1926). This species of Klebsiella is immobile, asporigenic, serologically linked, normally capsulated, responds to the Parr test as ++ , and shows varying fermentative capacities (Wheat et al., 1965).

KR can be differentiated from other subspecies based on its biochemical characteristics (positive test results for methyl red, negative for urease, and negative for citrate reductase) and on its capsular (K) and somatic (O) antigens. All strains of Klebsiella Pneumoniae Rhinoscleromatis are of capsular type 3 (K3) (Gaafar et al., 2000).

\subsection{Incongruity of etiology and diagnosis}

The role of KR as the only etiologic agent of RS has always generated doubts, and researchers often failed in experimentally reproducing the disease. In the 1920 s to 1930 s, attempts were made to transmit the disease by intravenous and subcutaneous injections of $\mathrm{KR}$ into mice and monkeys (Gaafar et al., 2000) with appearance within a few days of a scleromatous granuloma that quickly regressed, leaving no scar traces. The same results were obtained by inoculating KR in the front eye chamber or in the nasal mucosa; in the latter case, lesions were more stable and regressed more slowly, indicating a weakness of the respiratory system to eliminate the bacteria (Gaafar et al., 2000). When trying to reproduce the disease in humans by injecting KR or macerated granulomatous tissue in the nose, a completely negative outcome was reported (Gaafar et al., 2000). It is clear that the 
simple contagion with $\mathrm{KR}$ is not sufficient to determine the disease in humans and animals.

Diagnosis of RS is determined by biopsy of the affected tissue and identification of the pathognomonic Mickulicz cells (granulomatous lesions with vacuolated histiocytes) and of Russell bodies (plasma cells with particular intracytoplasmic inclusions); however, detection of Mickulicz cells may be challenging especially in the late fibrotic stage of the disease (Ahmed et al., 2015; Zhong et al., 2011). In fact, in the late stages of RS, the biological and histological identification of the causative bacterial agent is not always possible; in such circumstances the definitive diagnosis relies on histopathological analysis and on identification of morphological features of the disease by excluding in the differential diagnosis other chronic nonspecific inflammatory lesions (Ahmed et al., 2015).

\subsection{Pathological aspects}

In peripheral blood, cell-mediated immunity is quantitatively abnormal; leukocytes and lymphocytes are within normal range while it is often observed an absolute reduction of $\mathrm{CD} 3+$ and a relative reduction of $\mathrm{CD} 4+$, an increase in the absolute value of $\mathrm{CD} 8+$ and the inversion of the $\mathrm{CD} 4+/ \mathrm{CD} 8+$ ratio (Fusconi et al., 2011; Fusconi et al., 2006). Moreover, studies have shown an increase in Natural Killer $(\mathrm{CD} 56+)$ and $\mathrm{CD} 8+\mathrm{CD} 56+$ double-labeled leucocytes. In tissues affected by $\mathrm{RS}$, immunohistochemical studies revealed one-third of T-lymphocyte population having a CD3+/CD8+ (cytotoxic/suppressor) and two-thirds of T-lymphocytes exhibiting a CD3+/CD4+ (Helper/inducer)

profile (Maguina et al., 2006). Numerous mature B-lymphocytes have also been described, presumably the precursors of the numerous plasma cells described in RS.

\subsection{Aspects of ineffective immune system}

The presence of B cells reinforces the view that two components of the immune system are involved in tissues affected by RS: 
a) humoral response given by the B-lymphocytes, ineffective because KR is an intracellular pathogen (Fusconi et al., 2011; Fusconi et al., 2006);

b) a qualitatively ineffective granulomatous Th1 reaction that does not stop the disease; the ineffectiveness of the Th1 granulomatous reaction is also demonstrated by the complete anarchy of the T-lymphocyte distribution (Kasper et al., 2004).

Furthermore, within the granuloma there are neither Natural Killer (CD56+) cells nor CD8+ CD56+ double-labeled leucocytes, crucial for the initiation and regularization of Th1 reaction. Actually, also the innate immune system appears to be ineffective (Fevre et al., 2013).

We believe that the chronicity of the disease may be a consequence of the aforementioned anomalies of the immune system behavior. It is not known why this occurs: does KR prevent the immune system to mount an adequate response, or else is the immune system already altered, thus allowing the microorganism to induce the pathological condition? The authors postulate that RS is a kind of immunodeficiency in which there is a qualitative reduction of the lymphocytes intervention, that are hyporeactive to KR.

\subsection{Geographical and genetic evidences}

Although a rare disease, RS has been reported in several case series in countries in the Middle East, Eastern Europe, North and Sub-Saharan Africa, Indonesia, Central and South America. Often, an "extrinsic factor" has been sought, giving importance to socio-environmental conditions (hygiene, economic status, nutritional status, rural environment, etc.) that are capable of affecting the onset of the disease. In particular, the disease is present only in some nations and it affects predominantly rural and economically poor areas (Kim et al., 2003; Mukara et al., 2014). However, a subsequent study of social geography showed that poverty and the working activities of these areas are similar to those in the neighbor regions, where the disease is unknown or sporadic (Allah et al., 2013).

Several cases of RS have been reported in Europe. The largest number originate from Central Europe, especially in the area of the Black and Caspian Seas (Muzyka and Gubina, 1972) and Poland, where 
the authors described a group of 32 children with scleroma from the endemic areas in the Province of Lublin (Klonowski et al., 1974). Only a few cases have been reported in Western Europe during the past 15 years (de Pontual et al., 2008), showing a progressive reduction of incidence of RS in this geographical area. Sardinia, an Italian island where RS have been extensively reported in the past, had the highest number of cases, followed by Spain (Fernandez-Vozmediano et al., 2004), Switzerland (Nayak et al., 2015), Germany (Paul et al., 1993), France (Botelho-Nevers et al., 2007; de Pontual et al., 2008), Portugal (Simao et al., 2014), and United Kingdom (Hart and Rao, 2000). In Switzerland, of 35 cases collected by Barraud, 30 were from the area of Valais (Nayak et al., 2015). In Sardinia, 23 cases of RS have been described between 1959 and 1969; 6 were reported in the area of Cagliari, one in Sassari and 16 in the area of Nuoro. In this area, about $70 \%$ were present in only 4 small towns in an area called Ogliastra (Oliena, Trieli, Balnei, Lanusei). It is unlikely that the working activities and the social status of the population of the involved towns may alone justify the data. Recently, it has been highlighted that some sub-populations of Sardinia, such as those in the Ogliastra area, are characterized by a high degree of isolation and genetic homogeneity. The low genetic variability between geographical subpopulations makes these populations optimal for studying and understanding the genetic causes of conditions of unknown etiology. It is conceivable that because of the genetic homogeneity in these areas, the easy and frequent transmission of a possible genetically induced condition favors the predisposition to KR infection.

Similar evidences were found in other countries: in Guatemala the disease was almost unknown until 1959 in the northwestern region, while it was endemic in the southeastern region, although these two regions had identical economic conditions and the same ethnic composition. Maguina et al described eight patients with RS in Peru from 1996 to 2003 (Maguina et al., 2006). Recently, more reports of RS in Sub-Saharan countries have been published. In 2012, Elola et al reported two cases of RS in Burkina Faso (Elola et al., 2012). N'gattia et al described the epidemiological, clinical and therapeutic aspects of RS in university hospitals in Sub-Saharan countries. The authors described 14 cases of RS; 
the majority of the patients were natives of Côte d'Ivoire, Burkina Faso, Mali and Guinea; these countries are considered endemic for RS (N'Gattia K et al., 2011).

In a retrospective study on RS in French University Hospitals during a 16-year period, the authors reported an elevate occurrence of early-onset RS in multiplex and/or consanguineous families, suggesting that genetic control of the host response to KR may be involved in the pathogenesis of RS in endemic areas (de Pontual et al., 2008). Additional evidence of RS in consanguineous families is available in the literature: Fernández-Vozmediano et al reported RS in three siblings, posing special attention on recognizing the clinical signs characteristic of RS (Fernandez-Vozmediano et al., 2004). Hara in 1957 described seven cases of RS in a Mexican family, involving the father, the mother, one son and four daughters. All children were born in the United States (Hara, 1957). Block reported a family history of RS for $17.2 \%$ of his patients (Block, 1938). Cunnings reported two cases of RS in two native-born brothers (Cunning, 1947).

Specific genetic features have been investigated in patients affected by RS. In 1993, Martin et al found HLA-DQ3 as a common allele in a family of six members affected by RS, demonstrating familial segregation with RS (Martín, 1993). In a more recent study, Sánchez-Marín et al compared nine RS patients and 163 healthy controls and demonstrated a significant association between DQB1*0301 and susceptibility to RS. The authors proposed that DQA1*03011-DQB1* 0301 haplotype may be a strong risk factor for development of RS; in their study individuals carrying DQ3 had 58\% more risk to develop RS than those with another haplotype (Sanchez-Marin et al., 2007). These epidemiological data constitute the basis to look for individual genetic or epigenetic factors, possibly in combination with environmental factors such as biological underpinnings of the disease (Sanchez-Marin et al., 2007; Tan et al., 2012).

\section{Conclusions}

Despite robust evidence for a clear association between $\mathrm{RS}$ and $\mathrm{KR}$, the sole presence of KR infection may be unable to determine the onset of the disease. Individual factors of the host are important, as 
well as the observation that RS often affects whole families and, especially, close relatives. This fact, in association with information on the social geography of the disease, allows us to hypothesize that organic predisposition, possibly of genetic or epigenetic origin, may play a role in KR infection and in determining the onset of RS. This intrinsic factor, in relation to genetic transmission, would affect the immune system, particularly lymphocytes, making it less effective against KR. To date, the search for the "intrinsic" factor of the RS has never been sufficiently considered. For many years, the undisputed acceptance of the thesis of an infectious disease associated to an "extrinsic" factor such as hygienic conditions, poverty, inadequate nutrition, has led to a delay in clinical research. Based on the overall picture, we propose, instead, that intrinsic factors may give rise, or crucially contribute, to the disease. Genetic risks or susceptibility genes might be searched by performing genome-wide association studies or epigenomic studies.

\section{References}

Ahmed, A.R., El-Badawy, Z.H., Mohamed, I.R., Abdelhameed, W.A., 2015. Rhinoscleroma: a detailed histopathological diagnostic insight. Int J Clin Exp Pathol 8, 8438-8445.

Airas, L., Jalkanen, S., 1996. CD73 mediates adhesion of B cells to follicular dendritic cells. Blood $88,1755-1764$.

Allah, K.C., Kossoko, H., Assi Dje Bi Dje, V., Yeo, S., Richard Kadio, M., 2013. [Giant rhinoscleroma]. Rev Stomatol Chir Maxillofac Chir Orale 114, 184-186.

Barraud, A.M., 1926. Rinoscleroma. Zbl HNO, 391-398.

Berron, P., Berron, R., Ortiz-Ortiz, L., 1988. Alterations in the T-lymphocyte subpopulation in patients with rhinoscleroma. J Clin Microbiol 26, 1031-1033.

Block, S.G., 1938. Familial Scleroma of the Upper Respiratory Passages. Zhur. usl. nos. i. gorl. bolez. 15, 157. 
Botelho-Nevers, E., Gouriet, F., Lepidi, H., Couvret, A., Amphoux, B., Dessi, P., Raoult, D., 2007. Chronic nasal infection caused by Klebsiella rhinoscleromatis or Klebsiella ozaenae: two forgotten infectious diseases. Int J Infect Dis 11, 423-429.

Cunning, D.S., 1947. Rhinoscleroma in two native-born brothers. Arch Otolaryngol 46, 570.

De Pontual, L., Ovetchkine, P., Rodriguez, D., Grant, A., Puel, A., Bustamante, J., Plancoulaine, S., Yona, L., Lienhart, P.Y., Dehesdin, D., Huerre, M., Tournebize, R., Sansonetti, P., Abel, L., Casanova, J.L., 2008. Rhinoscleroma: a French national retrospective study of epidemiological and clinical features. Clin Infect Dis 47, 1396-1402.

Di Carlo, R., D'Agostino, L., Cassano, L., Grandi, E., Pastore, A., 2001. [Rhinoscleroma with extramaxillary extension: report of a clinical case]. Acta Otorhinolaryngol Ital 21, 254-259.

Efared, B., Hammas, N., Gabrielle, A.E., Ben Mansour, N., El Fatemi, H., Chbani, L., 2018. Rhinoscleroma: a chronic infectious disease of poor areas with characteristic histological features - report of a series of six cases. Trop Doct 48, 33-35.

Elola, A., Gyebre, Y.M., Ouattara, M., Ouoba, K., 2012. [Rhinoscleroma: two cases in BoboDioulasso in Burkina Faso]. Med Sante Trop 22, 409-411.

Fernandez-Vozmediano, J.M., Armario Hita, J.C., Gonzalez Cabrerizo, A., 2004. Rhinoscleroma in three siblings. Pediatr Dermatol 21, 134-138.

Fevre, C., Almeida, A.S., Taront, S., Pedron, T., Huerre, M., Prevost, M.C., Kieusseian, A., Cumano, A., Brisse, S., Sansonetti, P.J., Tournebize, R., 2013. A novel murine model of rhinoscleroma identifies Mikulicz cells, the disease signature, as IL-10 dependent derivatives of inflammatory monocytes. EMBO Mol Med 5, 516-530.

Fusconi, M., Gallo, A., De Virgilio, A., Natalizi, S., Greco, A., Zambetti, G., de Vincentiis, M., 2011. B lymphocyte subsets in patients with rhinoscleroma. Otolaryngol Head Neck Surg 144, 809814.

Fusconi, M., Pulice, G., Ippoliti, F., Mastronicola, R., Ralli, G., de Vincentiis, M., 2006. Modification of lymphocyte subsets in patients with rhinoscleroma. Am J Otolaryngol 27, 401-405. 
Gaafar, H.A., Bassiouny, M., El Mofty, M., Badour, N.M., Nour, Y.A., 2000. Experimental intravenous inoculation of Klebsiella rhinoscleromatis bacilli in albino rats: a histopathological and bacteriological study. Acta Otolaryngol 120, 279-285.

Griswold, D.E., Badger, A.M., Bender, P.E., Sitrin, R.D., Antell, L., Greig, R.G., Poste, G., 1983. Differential effects of intact subunits and nicked fragments of concanavalin A on immune functions in vitro and in vivo. J Immunol 131, 1626-1628.

Hara, H.J., 1957. Scleroma; observations on seven cases in one family for 10 years and another case which developed intracranial complications after five years. Laryngoscope 67, 695-708.

Hardy, R.R., Carmack, C.E., Shinton, S.A., Kemp, J.D., Hayakawa, K., 1991. Resolution and characterization of pro-B and pre-pro-B cell stages in normal mouse bone marrow. J Exp Med $173,1213-1225$.

Hart, C.A., Rao, S.K., 2000. Rhinoscleroma. J Med Microbiol 49, 395-396.

Kasper, H.U., Hegenbarth, V., Buhtz, P., 2004. Rhinoscleroma associated with Rosai-Dorfman reaction of regional lymph nodes. Pathol Int 54, 101-104.

Kim, N.R., Han, J., Kwon, T.Y., 2003. Nasal rhinoscleroma in a nonendemic area: a case report. J Korean Med Sci 18, 455-458.

Klonowski, S., Golabek, W., Borowko, A., Suwala, H., Nowakowska, M., 1974. [Endemic scleroma of the respiratory tract in childhood]. Pol Tyg Lek 29, 787-789.

Maguina, C., Cortez-Escalante, J., Osores-Plenge, F., Centeno, J., Guerra, H., Montoya, M., Cok, J., Castro, C., 2006. Rhinoscleroma: eight Peruvian cases. Rev Inst Med Trop Sao Paulo 48, 295299.

Martín, A.L., Flores, S.G., Terán, L.O., Arroyo, C.M., Orea, S.M., Camarena, A., 1993. Estudio inmunogenético de una familia con escleroma. An Otorrinolaringol Mex 38, 99-101.

Modlin, R.L., Hofman, F.M., Meyer, P.R., Sharma, O.P., Taylor, C.R., Rea, T.H., 1983. In situ demonstration of T lymphocyte subsets in granulomatous inflammation: leprosy, rhinoscleroma and sarcoidosis. Clin Exp Immunol 51, 430-438. 
Mukara, B.K., Munyarugamba, P., Dazert, S., Lohler, J., 2014. Rhinoscleroma: a case series report and review of the literature. Eur Arch Otorhinolaryngol 271, 1851-1856.

Muzyka, M.M., Gubina, K.M., 1972. Problems of the epidemiology of scleroma. 2. Some aspects of the problem of endemic focus formation. J Hyg Epidemiol Microbiol Immunol 16, 8-20.

N'Gattia K, V., Kacouchia, N., Koffi-N'guessan, L., Mobio, N.M., Kouassi-Ndjeundo, J., Kouassi, M., Yoda, M., Vroh Bi, T.S., 2011. Retrospective study of the rhinoscleroma about 14 cases in ENT departments of university hospitals (Cote d'Ivoire). Eur Ann Otorhinolaryngol Head Neck Dis $128,7-10$.

Nayak, P., R, C.P., K, V.S., Desai, D., Pandit, S., Ingaleshwar, P.S., 2015. Rhinoscleroma of nose extruding into oral cavity. J Coll Physicians Surg Pak 25 Suppl 1, S27-29.

Paul, C., Pialoux, G., Dupont, B., Fleury, J., Gonzalez-Canali, G., Eliaszewicz, M., Sansonetti, P., Genereau, T., 1993. Infection due to Klebsiella rhinoscleromatis in two patients infected with human immunodeficiency virus. Clin Infect Dis 16, 441-442.

Quevedo, J., 1949. Scleroma in Guatemala, with a study of the disease based on the experience of 108 cases. Ann Otol Rhinol Laryngol 58, 613-645, illust.

Sanchez-Marin, L.A., Bross-Soriano, D., Arrieta, J., Kawa-Karasik, S., Martinez-Vilchis, V., Jimenez-Lucio, R., Olivo-Diaz, A., 2007. Association of HLA-DQA1*03011-DQB1*0301 haplotype with the development of respiratory scleroma. Otolaryngol Head Neck Surg 136, 481-483.

Simao, I., Gaspar, I., Faustino, R., Brito, M.J., 2014. Rhinoscleroma in a 5-year-old Portuguese Child. Pediatr Infect Dis J 33, 774-775.

Tan, S.L., Neoh, C.Y., Tan, H.H., 2012. Rhinoscleroma: a case series. Singapore Med J 53, e24-27. Tedder, T.F., Klejman, G., Schlossman, S.F., Saito, H., 1989. Structure of the gene encoding the human B lymphocyte differentiation antigen CD20 (B1). J Immunol 142, 2560-2568.

Toppozada, H., Elsawy, M., Malaty, R., Dogheim, Y., 1984. The skin window test in rhinoscleroma contacts. J Laryngol Otol 98, 475-479. 
Wheat, R.W., Dorsch, C., Godoy, G., 1965. Occurrence of Pyruvic Acid in the Capsular Polysaccharide of Klebsiella Rhinoscleromatis. J Bacteriol 89, 539.

Zhong, Q., Guo, W., Chen, X., Ni, X., Fang, J., Huang, Z., Zhang, S., 2011. Rhinoscleroma: a retrospective study of pathologic and clinical features. J Otolaryngol Head Neck Surg 40, $167-$ 174. 